\title{
Patching together a world view
}

\author{
Data sets encapsulating the behaviour of the Earth system are one of the greatest technological \\ achievements of our age - and one of the most deserving of future investment.
}

T echnology can change the way we see the world. If the artist David Hockney is to be believed, the camera obscura changed the way artists drew things, and thus how their audiences saw them. Centuries later, photographic film changed the visual arts again, as painters sought to recapture subjectivity in fresh impressionisms and expressionisms in response to the new technology. Then cinematography brought with it a new mastery over time. Compressed, it turned buds to blooms in seconds - reversed, it re-erected falling chimneys with pleasing symbolic power. These tricks became embedded in our minds, letting us think of time moving backwards and forwards, faster and slower with an educated ease previously absent from the imagination.

In the past two decades, the computer has changed things yet again, introducing an almost infinite capacity to bring what was previously non-visual to the eye, and an almost infinite range of points of view impossible to reach in any other way. The ability to change pointof-view and depth-of-field massively and arbitrarily has created a peculiarly contemporary way of seeing, which American technology writer Steven Johnson has called "the long zoom". This is when a camera focused on, say, a human eye appears to hurtle pell-mell through the pupil to the nucleus of a cell - or pulls back from the orbit of the eye to an orbit round the planet.

In the world of the long zoom, the planetary scale has a particular significance. It links every image of the world to the great image of Earth that contains them all. It builds on and subverts the change first introduced by space flight almost 50 years ago - the ability to stand outside what was previously seen only from within. The long zoom integrates the inside and the outside, giving computers a means of marshalling vast data sets - as users of Google Earth can testify. Geospatial imagery becomes a great uniter of data; whether the data come from satellites looking down, or sensors deep in the oceans, or tracking systems strapped to walruses or gas monitors sitting above forest canopies, computers can, in principle, put them all together (see articles starting on page 778). This is why seemingly arcane developments such as the European Union's INSPIRE directive, a measure that tidies up access to geodata and provides an Internet portal for accessing them, are important. They set the standards by which the world can be freely reassembled.

\section{The long view}

The creation of these new ways of seeing the world would be a significant aesthetic achievement even if they had no commercial, scientific or strategic use. In fact they have all three - as well as an even greater environmental usefulness. After the expansion of human population, intensive agriculture and industrial development that marked the twentieth century, it is only with the help of global monitoring systems that today's arrangements of everything from urbanization to epidemiology can be properly understood.

One of the most profound contributions to this approach came from the late David Keeling, a pioneer of climate research who was the first person reliably to measure carbon dioxide levels at remote locations such as Mauna Kea in Hawaii or the South Pole, in what his friend and boss Roger Revelle famously called mankind's "great experiment" with the planet's climate. Keeling's simple instruments became the basis of a network

"Ideas not followed through can be taken up again later. A record not made is gone for good." around the world for monitoring trace gases. At various times it was suggested to Keeling that he should perhaps desist from taking such endless care over a single data stream - that this wasn't the basis of great science. It took courage and conviction to keep going - and even now, his heirs struggle to continue the work in the face of unwilling funders and apathetic peers (see page 789).

\section{Now or never}

Monitoring the Earth system requires great expertise, not just to build the instruments but to use them properly and interpret their output. Many scientists are, however, far from enthused by projects that do not involve the forming and testing of hypotheses. At worst, monitoring is traduced as stamp collecting and looked down on as drudgery.

Such attitudes must not be allowed to prevail. Testing hypotheses about how the world works requires not just information on the current state of the three-dimensional globe, but on its progress through the fourth dimension of time. Data on the colour of the seas that are not gathered today can never be gathered in the future - gaps left in the record cannot be filled (see page 782). And continuous data sets are going to be vital to the validation of the ever more informative models of the Earth system that we need.

This is why operational systems for data collection in which scientists play key roles are so important. Only they can give us multiscale and multifactor ways of seeing the world that are up to the challenges of the twenty-first century. When the expenditure needed to maintain these data flows conflicts with the funds needed to support fresh scientific research, researchers must acknowledge that there is a strong case for preferring continuous, operational monitoring. An accurate and reliable record of what is going on can trump any particular strategy for trying to understand it.

There is only one Earth, with only one history, and we get only one chance to record it. Ideas not followed through can be taken up again later. A record not made is gone for good. Long zooms in and out of our ever more detailed images of Earth will delight and inform us for years to come. But no digital trickery can replace the steady, fateful pan from past to future. 